\section{Nuevos rumbos para la Revista/Journal}

\author{
María L. Clark ${ }^{1}$
}

Quienes hayan leído los números más recientes de la Revista Panamericana de Salud Pública/ Pan American Journal of Public Health habrán tomado nota de un acontecimiento sin precedentes en la historia de esta publicación: la creación de un Consejo Editorial. Este grupo asesor, integrado por diez renombrados salubristas e investigadores de todas las subregiones del continente americano, se reunió con altos funcionarios de la Organización Panamericana de la Salud (OPS) y con los miembros de nuestra redacción por vez primera en Washington, D.C., el 5 y 6 de octubre de 2000. La riqueza de las aportaciones y la productividad de los debates en ese encuentro inicial estuvieron a la altura de toda expectativa. De hecho, apenas iniciadas las deliberaciones en torno a la revista, se hizo patente la futilidad de toda discusión sin antes despejar el más fundamental de los interrogantes: ¿Qué es la Revista/Journal? ¿Es una publicación científica independiente, en su orientación y contenido, del organismo al que pertenece, o una revista eminentemente institucional, portavoz de la OPS y transmisora de información científica filtrada por los lentes de la institución? Y al final todos coincidimos en que la revista no puede, ni debe, ser exclusivamente una cosa ni la otra, puesto que de su privilegiada posición entre ambas posturas dependen, precisamente, su singularidad y su capacidad para ofrecer a los lectores lo que no pueden brindarle otras revistas dedicadas a la salud pública en este continente.

La Revista/Journal es, por un lado, un órgano difusor de la labor de investigadores independientes, cuyos trabajos somete a un riguroso arbitraje por expertos. Simultáneamente, su vínculo con la OPS le confiere la singular capacidad para dar a conocer un amplio y equilibrado repertorio de experiencias nacionales que pueden servir de modelos y fuentes de inspiración para otros países dedicados a subsanar sus problemas sanitarios y las deficiencias de sus sistemas y servicios de salud. Cabe tener presente que la salud pública, profundamente afectada hoy en día por el fenómeno de la economía mundializada, es ámbito de acción de una creciente variedad de entidades y sectores - el Estado, el sector corporativo, las aseguradoras, los organismos unilaterales y multilaterales, los centros de investigación, el sector educativo, la sociedad civil organizada-, y en su posición como organismo internacional que brinda asesoramiento y asistencia técnica a toda la Región, la OPS pulsa el ritmo al que se mueven todo un continente y cada uno de sus países en materia de salud. Esta doble identidad como publicación autónoma y a la vez poseedora de una amplia perspectiva institucional distingue y enriquece a la Revista/Journal.

Habiendo entrado de lleno en el nuevo milenio, nos enfrentamos a la necesidad imperiosa de adaptar la Revista/Journal a las exigencias de un nuevo panorama epidemiológico, social, económico y político, y de adelantos técnicos y científicos que se producen a un paso vertiginoso. A los ojos de esta redacción, tan diverso es el público que lee la revista —salubristas, investigadores, médicos generales y especializados, administradores de servicios de salud, expertos en ciencias sociales, personal de enfermería, profesores universitarios, estudiantes de medicina, personal técnico de salud, etc., situados en cada rincón de este vasto territorio americano, desde la tundra canadiense hasta el extremo meridional de América del Sur- que abarcar tan amplio abanico temático en una sola publicación es prácticamente imposible. Para ello existe toda una gama de revistas especializadas que cumplen admirablemente bien esta función. Más bien, nuestra redacción aspira a concentrarse en cultivar y reforzar aquellos rasgos que le confieren a la Revista/ Journal su carácter distintivo, su singularidad entre otras revistas de similar orientación.

Con plena conciencia de que las estadísticas solo cobran valor y utilidad cuando sirven para avanzar de la teoría a la práctica, es nuestra intención limitar el número de artículos descriptivos que presentan datos epidemiológicos locales, procurando aumentar el de trabajos que versan sobre intervenciones de eficacia comprobada mediante métodos de evaluación apropiados, o que describen técnicas y enfoques novedosos. Asimismo, se dará creciente cabida a artículos y otros materiales relacionados con el estudio y la evaluación de los sistemas y servicios de salud, en sus aspectos cualitativos, administrativos y económicos. En resumen, la revista se propone, de ahora en lo sucesivo, dar prioridad a la publicación de materiales cuya temática y enfoque guarden relación, directa o indirecta, con la toma de decisiones y la definición de las políticas de salud. Y con miras a 
presentar ante el lector los resultados de la investigación de manera más aprovechable, figura entre nuestras metas inmediatas publicar más temas de actualidad, artículos de revisión de alcance regional y editoriales que permitan enfocar en su debida perspectiva y con ánimo comparativo los problemas de salud que aquejan a nuestros países y las medidas emprendidas para combatirlos.

Conscientes, además, de que los investigadores constituyen solamente una fracción, quizá minoritaria, del auditorio de nuestra revista - no así de sus autores, obviamente-, también estamos atentos a los intereses de aquellos lectores que se ocupan de los aspectos administrativos y gerenciales de la salud. Asimismo, las ciencias sociales, cuyo instrumental teórico y metodológico tiende a ser minusvalorado en algunos círculos por su dependencia de observaciones cualitativas teñidas por el subjetivismo, tampoco pueden en modo alguno desligarse de la salud pública, tan indisputable es la asociación entre el estado físico y mental y la adquisición de hábitos insalubres, por un lado y, por el otro, las circunstancias materiales y sociales del individuo y la colectividad. Es un hecho lamentable que relativamente pocas revistas indizadas en las bases de datos de las disciplinas biomédicas, salvo algunas brasileñas y mexicanas, publican con regularidad sobre las ciencias sociales en su relación con la salud. La Revista/Journal, consciente de esta relación, busca enriquecerse con las aportaciones de expertos en estas disciplinas.

Como antídoto contra la fosilización ideológica y práctica, la redacción de la Revista/Journal desea fomentar el debate sobre políticas e intervenciones y sobre los problemas que en la actualidad enfrentan los sectores sanitarios de los distintos países. Para lograrlo, aspira a recurrir a un mayor número de artículos de reflexión y análisis, cartas a la redacción, comentarios críticos y otros recursos similares. Como en años anteriores, se seguirán publicando números monográficos sobre temas de especial importancia; la equidad y la salud y la equidad como componente del proceso de reforma del sector sanitario son dos de los temas que tenemos previsto explorar en el futuro cercano.

El interés internacional en los problemas de salud pública de América Latina y el Caribe se hace cada vez más patente en el creciente número de artículos que sobre ellos aparecen últimamente en revistas prestigiosas de Europa y América del Norte. No obstante, el desconocimiento del inglés sigue siendo un obstáculo para buena parte de la comunidad científica latinoamericana monolingüe que aspira a dar a conocer los frutos de sus investigaciones o de conocer las aportaciones de colegas que se expresan en su mismo idioma. En este sentido, la Revista/Journal representa para ellos un recurso insustituible. Teniendo en cuenta, además, que la investigación no es un fin en sí mismo — quizá solo para aquella minoría movida por el exclusivo afán de cosechar méritos académicos-, sino una exploración de la realidad con miras a transformarla, aprovechando al máximo los recursos a disposición, es justo, incluso obligatorio desde un punto de vista ético y humano, que sus resultados se coloquen primariamente al alcance del público que podría sacarles mayor beneficio. En el caso de la Revista/Journal, una fracción muy grande de ese público radica en América Latina. En vista de ello y de que su trilingualismo es otra de las singularidades y ventajas que ofrece la Revista/Journal en comparación con otras publicaciones de su género, procuraremos pronto adoptar algunas medidas para satisfacer de manera más completa las necesidades de los lectores monolingües, como la redacción de resúmenes de una longitud mayor de la habitual (en inglés para acompañar a los artículos en español o portugués y viceversa), o la traducción de artículos seleccionados a pedido de los suscriptores de la revista, bien sea individualmente o en una publicación suplementaria anual. Adicionalmente, se observarán a partir de este número algunos cambios menores, como la traducción entre corchetes de los títulos en el índice de materias y la inclusión de palabras clave para facilitar la búsqueda en bases de datos.

Tales son, hasta ahora, algunos de los resultados inmediatos de la labor conjunta recién iniciada entre nuestra redacción y el Consejo Editorial, del cual nos sentimos justificadamente orgullosos. La intención es publicar una revista de mayor valor práctico, más dinámica y estimulante, más encaminada hacia el análisis, la polémica y la expresión de puntos de vista divergentes, siempre con miras a vincular los resultados de la investigación con la definición de políticas. No obstante, nuestro cometido primordial es servir a quienes leen nuestra publicación, y para conseguirlo necesitamos conocer a estos lectores, entender sus necesidades y preferencias, saber en qué medida satisfacemos sus expectativas y contribuimos al mejor desempeño de su labor. Con estos fines apelamos a cada uno de ustedes, estimados lectores, solicitándoles que nos envíen sus opiniones, comentarios y sugerencias por escrito a fin de lograr, entre todos, llevar a la Revista/Journal a ocupar el más destacado lugar entre las revistas de salud pública de la Región. 